Western University

Scholarship@Western

$4-1-2020$

\title{
The Networked Question in the Digital Era: How Do Networked, Bounded, and Limited Individuals Connect at Different Stages in the Life Course?
}

\author{
Barry Wellman \\ University of Toronto \\ Anabel Quan-Haase \\ The University of Western Ontario, aquan@uwo.ca \\ Molly-Gloria R. Harper \\ Western University
}

Follow this and additional works at: https://ir.lib.uwo.ca/fimspub

Part of the Community-Based Research Commons, Family, Life Course, and Society Commons, and the Library and Information Science Commons

Citation of this paper:

Wellman, B., Quan-Haase, A., \& Harper, G. M. (2019). The networked question in the digital era: How do networked, bounded, and limited individuals connect at different stages in the life course? Network Science, 8(3), 291-312. https://doi.org/https://doi.org/10.1017/nws.2019.28 
The Networked Question in the Digital Era:

How Do Networked, Bounded, and Limited Individuals Connect at Different Stages in the Life Course?

\author{
Barry Wellman \\ NetLab \\ Anabel Quan-Haase \\ Western University \\ Molly-Gloria R. Harper \\ Western University
}

Running head: The Networked Question in the Digital Era 


\title{
The Networked Question in the Digital Era:
}

\section{How Do Networked, Bounded, and Limited Individuals Connect at Different Stages in the}

\section{Life Course?}

\begin{abstract}
We used in-depth interviews with 101 participants in the East York section of Toronto, Canada to understand how digital media affects social connectivity in general--and networked individualism in particular--for people at different stages of the life course. Although people of all ages intertwined their use of digital media with their face-to-face interactions, younger adults used more types of digital media and more diversified personal networks. People in different age-groups conserved media, tending to stick with the digital media they learned to use in earlier life stages. Approximately one-third of the participants were Networked Individuals: In each age-group, they were the most actively using digital media to maintain ties and to develop new ones. Another one-third were Socially Bounded, who often actively used digital media but kept their connectivity within a smaller set of social groups. The remaining one-third, who were Socially Limited, were the least likely to use digital media. Younger adults were the most likely to be Networked Individuals, leading us to wonder if the percentage of the population who are Bounded or Limited will decline over time.
\end{abstract}




\section{The Networked Question in the Digital Era}

The networked question examining the nature and composition of personal networks in the digital era has developed from the long-standing debate around the "community question" (Wellman, 1979). 19th century observers such as Tönnies (1887) argued that urbanization and industrialization were tearing people away from densely knit villages into isolated life in burgeoning big cities where few neighbors knew each other's names. His--and similar-arguments were deductive, fueled by pastoralist nostalgia that assumed without evidence that because village-like life was declining, community was becoming anomically isolated (e.g., Tönnies, (1887 [1955]; Weber, 1922 [2009]; Wirth, 1938). However, researchers have moved beyond armchair theories and have provided systematic ethnographic and survey evidence (e.g., Gans, 1962; Greer, 1962) since the 1960s that local communities continue to thrive in villages and big cities (see the reviews in Wellman \& Leighton, 1979; Hampton \& Wellman, 2018).

To further this debate, Rainie and Wellman (2012) argued against dystopian views favoring the "death of community" and provided evidence that strong bonds continue to exist, with new technologies integrating in-person with internet and mobile means of connection. They argued that individuals continue to socialize, but not in bounded groups, rather as networked individuals. Networked individualism indicates a society that has shifted away from a model where personal networks are embedded in bounded groups, what Tönnies called Gemeinschaft and Durkheim referred to as mechanical solidarity, to a society of more loosely connected networks that resembles Durkheim's (1893) organic solidarity and builds on Simmel's (1922) description of a web of multiple, overlapping, and only partial connected networks. With proliferating digital and mobile media, " $[\mathrm{t}] \mathrm{his}$ is a time for individuals and their networks, not for groups. The all-embracing collectivity (Parsons, 1951) ... has become a fragmented, personalized 
network. Autonomy, opportunity, and uncertainty rule today's community game" (Wellman, 2001, p. 248).

Although "networked individualism" has been an intriguing concept since 2001

(Wellman, 2001), this is the first paper to examine it empirically. The concept--individuals interconnected through multiple, partial networks--initially developed as a theoretical orientation. While the concept has received scholarly attention ${ }^{1}$ and anecdotal support, there has not been any systematic evidence evaluating its prevalence in the digital era at different stages of the life course.

To evaluate this concept, we first present an approach to assess the extent to which people are networked individuals. Second, as different age-groups may vary in their personal networks and use of digital media, we establish the basic network characteristics of different agegroups, finding that not all are networked individuals. We contrast:

(a) Networked Individuals maneuvering through multiple, partial personal networks and groups;

(b) Socially Bounded individuals embedded in only a few groups such as kin or neighbors;

(c) Socially Limited individuals with fewer ties.

We go on to examine how those in different kinds of personal networks vary in their use of digital media. Finally, we show how different types of connectivity and digital media use vary at different stages of the life course.

From the Community Question to the Networked Question

${ }^{1}$ Google Scholar, May 10, 2019: 4,740 citations. 
"The community question" asks how communities change over time and the role played by urbanization, industrialization, and technology. The "community question" asked a generation ago (Wellman, 1979) if new forms of connectivity had liberated personal networks from being predominantly local. Were kin and friends still predominantly enmeshed in densely knit, bounded networks, or were new forms of community developing whose members were maneuvering among multiple networks to which they only had partial commitments? Analysts argued that with the proliferation of lower-cost long-distance telephone plans, automobiles, and plane travel, people had become less tied to local solidarities (Wellman, 1988; Wellman \& Tindall, 1993). The evidence showed that people in the Global North were less involved with organized groups--be they churches, sports clubs, or labor unions--and were turning instead to private spirituality and informal get togethers (Putnam, 2000; Campbell, 2012; Rainie \& Wellman, 2012). Homes were no longer castles and men were no longer the only household breadwinners as more women sallied forth to earn a living (Florida, 2014; Uchitelle, 2019), private cars replaced family cars, and rising costs, easier access to birth control, and divorce enabled and constrained women to do paid work (Kennedy \& Wellman, 2007).

The evidence suggests that although most people have local, neighborhood ties, most of their ties are not local (Fischer, 1982; Mok, Wellman, \& Basu, 2007; Mok, Wellman, \& Carrasco, 2010). For example, the first East York study found that only $13 \%$ of the socially close ties were in the same neighborhood (Wellman, 1979). In these multiple, partial networks, people in different role relations provide specialized social support: for example, neighbors tend to exchange small services such as childminding while many parents provide financial aid, and sisters often give brothers emotional support (Wellman \& Wortley, 1990). 
The networked question addressed in the present paper has grown out of the community question as applied in the era of digital media (Wellman, Quan-Haase, Hampton, \& Witte, 2001). The community question a generation ago still assumed home-based communication with extensive use of wired landline telephones and snail-mail deliveries. In the digital era, the proliferation of mobile connectivity--cellphones, tablets, and laptops--emphasized the individual as the connecting unit--wherever she may be. In these personal networks, the individual--and not the household or the kinship unit-- is even more of a hub for connectivity with personally-logged on internet and instant mobile connectivity in pocket or purse (Rainie \& Wellman, 2012; 2019). Distance and physical contact have become even less constraints as a result of free NorthAmerican-wide calling on most cellphones and the internet's ease of connecting to the world without additional charges. These developments have afforded opportunities for people to maintain ties over substantial distances and to rekindle them when they go fallow (see also Hampton, 2016; Mok, Wellman, \& Carrasco, 2010; Hampton \& Wellman, 2018). In such a networked society, people have a greater ability to reach into multiple social circles, but they often must network actively on their own rather than resting in the comfort of an allencompassing group.

It is no longer news that communities exist as personal networks. Yet, while the Global North has become networked, this does not mean that all members of these societies operate as networked individuals. Is digital media related to the size, composition, and structure of personal networks? Some are Networked Individuals, actively maneuvering among their own multiple, partial networks (Wellman, 2001; Rainie \& Wellman, 2012). Yet, some may remain ensconced in a few Socially Bounded groups of local communities, kinship circles, or social organizations (Walzer, 1992). Still others may face Socially Limited situations that scholars from Tönnies 
(1887) and Durkheim (1897) to Peplau (1982), Putnam (2000), and Turkle (2012) have warned about, with the lessening of neighborhood ties, kinship ties, and social group life leading to fewer traditional connections in a now-digital milieu (Loach \& Laverty, 2016) or having primarily superficial online relations based on likes, retweets, and reposts instead of rich face-to-face contact (Turkle, 2011).

\section{Putting a Life Course Perspective on the Networked Question}

A life course perspective helps to understand how individuals in different life stages vary in their network structure and composition and their digital media use. For example, shrinking social connections are major challenges in later life, especially after retirement and losing a partner (Cornwell \& Laumann, 2008; Cornwell \& Waite, 2009; Dickens et al, 2011). By contrast, young adults are in a phase where they are building their social networks and spend much energy in socializing and expanding their networks offline and online (boyd, 2007; Field, 2008; Hagestad \& Uhlenberg, 2005; Settersten \& Ray, 2010). Globally, younger age-groups are heavy users of social media sites such as Instagram and Facebook in comparison to older adults (Taylor \& Silver, 2019). By contrast, when older adults do use Facebook, their pattern of social connectivity differs significantly from that of younger adults. For example, there were agerelated differences in American Facebook users' network size and the proportion of their actual (valued social ties) to total Facebook friends (Chang, et al., 2015): older adults reported a higher proportion of actual to total Facebook friends, suggesting they maintain more emotionally rewarding and close relations. A life course perspective is also beneficial in examining patterns and narratives of media use (Robinson, et al., 2015), particularly because age differences in media adoption and use are a recurrent finding in much of the literature as discussed above (Taylor \& Silver, 2019) and are also recreated in prevalent media discourses in print, television, 
advertisement, and social media (Schreurs, Quan-Haase, \& Martin, 2017). Not only do younger adults tend to use different kinds of digital media, but they also use more kinds of digital media much more often (Anderson, 2015; Smith \& Anderson, 2018; Hargittai \& Dobransky, 2017; Hargittai, 2018).

Age ranges are often seen as life stages, although this conceptualization ignores cultural, social, historical, and political dimensions that influence when one stage starts and another ends. For example, aging in North America is often described as the period when one leaves the work force and starts retirement. Yet, when this stage in life begins can vary greatly across cultures and even within cultures (Elder, Johnson, \& Crosnoe, 2003). Hence, we treat age-groups as soft proxies for life stages, with the understanding that these pathways are fluent and influenced by sociocultural understandings as well as historical moments. Yet, these life stages are relevant because research suggests that they are related to the composition and structure of networks (Fung, Carstensen, \& Lang, 2001) as well as to media habits and preferences (Change et al., 2015; Quan-Haase et al., 2017).

Age-related differences found in past studies in network structure, composition, and media use motivate our research questions. As the nature of personal networks varies with stages in the life course (Hogan, 1981; Hogan \& Astone, 1986), also the extent to which people use digital media varies (Quan-Haase, Williams, Kicevski, Elueze, \& Wellman, 2018; Anderson, 2015). Yet, age-groups are not just people who are older or younger--they have tended to have different life experiences, especially as many older adults had less experience with digital media over the course of their lifetimes while the nimble fingers of younger adults show much comfort with mobile phones than even the middle-aged. How do these phenomena interact? Are older 
cohorts, often less involved with digital media and with smaller networks, less likely to be Networked Individuals (Ferguson \& Freymann, 2019)?

Despite the assertion of networked individualism in a networked society, there has been no attempt to measure it and assess its prevalence. The networked question has especial relevance to the life course: There is little understanding of how people at different stages of the life course, often with different orientations to digital media, vary in the extent to which their ties are Networked, Bounded, or Limited. In the present study, we examine:

Research Question 1: How do the personal networks and interaction patterns of individuals in different age-groups differ?

Research Question 2. Do Networked, Socially Bounded, and Socially Limited individuals differ in their use of digital media?

Research Question 3: How does social connectivity and digital media use vary in different stages of the life course?

\section{Methods}

\section{East York Context}

Data were collected as part of the fourth study taking place in the East York area of Toronto, building on our team's earlier research in this locality over five decades. The first study pioneered the treatment of community as social networks (Wellman, 1979), the second showed which role relations (e.g., immediate kin) provide what types of social support (Wellman \& Wortley, 1990), and the third proposed the rise of networked individualism (Wellman et al., 2006).

East York was an independent borough until 1998 (Toronto Neighbourhood Guide, n.d.; Payne \& Welch, 2015) but has since been amalgamated into the Greater Toronto Area (GTA), 
the fourth largest metropolitan area in North America with approximately 6.5 million residents (Payne \& Welch, 2015; Toronto Population, 2017). According to a 2018 Toronto City Planning report, East York's population reached nearly 120,000 residents, living primarily in small houses and high-rise apartment buildings. The median age of residents in East York was 36 years, with $13 \%$ of the population older than age 65 . East York comprised working-class and middle-class families with an average household income of $\mathrm{Cdn} \$ 113,802$ compared to Toronto's average household income of Cdn $\$ 102,721^{2}$. Sixteen percent of East Yorker's had a household income below Cdn \$20,000 (Toronto City Planning, 2018).

\section{Sample}

The fourth wave of East York studies interviewed 101 adult participants, ranging from 27 to 93 years of age $(M=60 ; S D=15)$. For our analysis, we divided participants into four agegroups: under 35 (6 participants), 35-50 (22 participants), 51-64 (32 participants), and 65 and older (41 participants). The sample comprised 55 women and 46 men. Representing the cultural diversity of Toronto (Toronto City Planning, 2018), 26\% of participants were Canadian-born and 74\% were born outside of Canada in Europe, the Middle East, Asia, and the Caribbean.

Regarding living arrangements: 29\% lived alone and were never married, or were divorced, 32\% lived with a spouse or partner, $25 \%$ lived with a partner in addition to children, and $15 \%$ had alternative living arrangements such as alone with children, or with siblings, relatives, or other types of shared accommodation. Half (49\%) worked full-time, 5\% worked part-time, 9\% were unemployed, and $38 \%$ were retired--reflecting the older age of the sample. The age bias could be a reflection of older participants having more time and thus willingness to participate in the study

${ }^{2} 1$ Cdn\$ usually equals approximately 75 US cents. 
by responding to the invitation letter, answering landline phone calls for an appointment, and taking time for an interview.

\section{Data Collection}

A Toronto-based sampling company provided a list of representative residents in East York. The sampling frame consisted of 2,321 East York households. Personal invitation letters were sent via mail to 304 residents randomly selected from the initial list and upon conducting follow-up telephone calls, 101 agreed in 2013-2014 to participate in the study, yielding a response rate of $33 \%$. Initial pilot testing allowed for the refining of questions and fine-tuning of the wording in the interview schedule (available at https://sociodigitaltest.files.wordpress.com/2017/12/interview-schedule_ni-project.pdf). Trained social science students conducted semi-structured, in-depth interviews with the participants that lasted 60-90 minutes. During these in-person interviews, participants were asked questions and probed about an array of topics pertaining to technology use, social networks, and social support. With permission from participants, all interviews were recorded and transcribed verbatim. Onethird of interview transcripts were checked for accuracy. Pseudonyms reflecting the participants' ethnicity and gender are used to protect confidentiality.

\section{Typology construction and categorization}

To build our typology we relied on the remarks of participants and coded these for both numeric and thematic analysis (Braun \& Clarke, 2006; Charmaz, 2014). Based on numeric coding of transcripts, we extracted the different role relations such as immediate kin, friend, and workmate that participants maintained; their involvement in social groups (see Wang, Zhang, \& Wellman, 2018; Quan-Haase, Wang, Wellman, \& Zhang, 2018), and finally their social interaction patterns. From the resulting statistics, we estimated key network measures such as the 
size and diversity of the participants' personal networks and then established cut-off points to develop the typology.

Measure 1: Network Size. Participants were asked about their active relationships with five types of social ties:

1. Immediate kin (e.g., children, partners, parents, siblings, and in-laws)

2. Extended kin (e.g., grandparents, aunts/uncles, and cousins)

3. Friends

4. Neighbors

5. Workmates.

Based on participants' responses, we counted the number of active social ties for each of the five role relations (Agneessens, Waege, \& Lievens, 2006). We then calculated the total number of social ties by adding all ties across all five role relations.

Measure 2: Social group involvement. Participants were asked about their participation in a wide range of social groups, such as religious groups, sports clubs, and volunteer organizations. For each social group in which they reported being engaged, we coded a "1" and summed.

Measure 3: Network diversity. We based the network diversity score on a combined measure of network size and social group involvement. (1) For the first step in calculating the network diversity score, we compared the number of social ties for each participant for each type of role relation (e.g., immediate kin, etc.) to the age-group median for that role relation. Participants were coded "0" if they reported no ties, " 1 " if their score was below or equal to the median in their age-group, and "2" if their score was above the median. The sum of scores across all role relations indicated their role diversity. For example, Harriet Morris (P23, W, 52) reported 
3 "friend" ties while the median for her age-group was 3.5, so Harriet Morris' value was below the median and she was coded as " 1 ".

(2) The second step for obtaining the network diversity score consisted of taking into consideration the measure of social group involvement. Participants were coded "0" if they reported no involvement in social groups, " 1 " if their score was below or equal to the median in their age-group, and "2" if their score was above the median. For example, for "group involvement" Harriet Morris (P23, W, 52) reported 2 social groups and the median for her agegroup was 1 , so her value was above the median and she was coded as "2".

(3) The third and final step in calculating the network diversity score was to add all the calculated scores across all five role relations and social group involvement. This yielded a network diversity score that ranged from "0" to " 12 "; with a median of 7 (S.D.=2.0).

Categorizing individuals by social connectivity. To construct our typology, we focused on the size, breadth, and diversity of participants' networks by categorizing them based on their values across the measures of network size, social group involvement, and network diversity (see also Quan-Haase et al., 2018; Wang et al., 2018). Participants whose value was above or equal to the median in all three measures were classified as Networked Individuals, those below the median in one of the three measures were classified as Socially Bounded individuals, and those equal to or below the median in all three measures were classified as Socially Limited individuals.

\section{Communication Channels and Devices}

During the interviews, participants were asked about their use of communication channels and ownership of devices. The participants primarily communicated across eight communication channels, of which two were traditional--face-to-face and phone calls (landline 
or cellphone)--and six channels were digital: email, texting, video-chat (e.g., Skype or Facetime), Facebook, Twitter, and LinkedIn. Participants were coded " 0 " if they did not use a particular communication channel and " 1 " if they did.

Digital Media Level. We employed responses to interview questions on communication habits to categorize participants in accord to their digital media level. Based on these responses, two measures were derived.

Measure 1: Digital media channels. Based on the total number of digital communication channels participants reported using, a score ranging from " 0 " to " 6 " digital communication channels was given; the median was $3($ S.D. $=1.7)$.

Measure 2: Total devices. Participants were also asked about the number of digital devices they own, which included computers (comprising both desktops and laptops), cellphones (including smartphones), and tablets. Responses were coded based on the number of devices participants reported owning across all categories. Participants owned a median of 3 (S.D.=1) devices.

Based on these two measures, those scoring above or equal to the median in both measures were classified as "high" because of their extensive involvement with digital channels across numerous devices. Those scoring above the median in one of the two measures were classified as "medium". Participants scoring equal to or below the median across both measures were classified as "low" due to minimal activity on digital media channels and the lack of devices owned to digitally engage. For example, Devon Edwards (P60, M, 70) reported being active on three digital communication channels (email, Facebook, and Twitter) and owning a total of seven devices. Since Devon scored equal to the median in measure one and above the median in measure two, Devon was classified as a "high" level participant. 
Thematic Analysis: To understand our three-fold typology and provide a strong foundation for discussion, we draw on our in-depth interviews and highlight illustrative quotes and contextual factors that influence how people network. We did a thematic analysis (Braun \& Clarke, 2006) to stay close to the data based on the characteristics of Networked Individuals that have been identified in the literature. During the process of thematic analysis, meetings among the team were frequent and memoing was extensive, with the coding scheme adjusted and refined as necessary. Participants' remarks were coded around their types of social ties, involvement in social groups, and the role of communication channels in their social lives. We organized these excerpts by research questions and annotated them with basic participant information (e.g., interview ID, gender, and age).

\section{Findings}

Research Question 1: How do the personal networks and interaction patterns of individuals in different age-groups differ?

To examine the personal networks and interaction patterns across age-groups in the East York sample, we looked at the size and role diversity of their networks, their involvement in social groups, and their uses of communication channels.

Network Size: The East Yorkers reported a median of $22(S . D .=13.9)$ ties in their networks, ranging between 6 and 95. Consistent with the life course literature, the number of social ties decreased with age (Table 1): the median for participants under 35 years of age was 34 ties $(S . D .=8.7), 35-50$ years of age had 21 ties $(S . D .=11.3), 51-64$ years of age had 15 ties $(S . D .=16.5)$, and those 65 or older had $14($ S.D.=13.3).

\section{Table 1 .}

Median number of types of social ties by age-group for type of connectivity

$\begin{array}{llllll}\text { Close Kin } & \begin{array}{l}\text { Extended } \\ \text { Kin }\end{array} & \text { Friends } & \text { Neighbors } & \text { Workmates } & \text { Overall }\end{array}$




\begin{tabular}{|c|c|c|c|c|c|c|}
\hline $\begin{array}{l}\text { All } \\
\text { Participants }\end{array}$ & 4 & 3 & 5 & 4 & 0 & 22 \\
\hline Under 35 & 5 & 6 & 9 & 7 & 5 & 34 \\
\hline $35-50$ & 4 & 3 & 5 & 4 & 6 & 21 \\
\hline 51-64 & 4 & 2 & 4 & 4 & 2 & 15 \\
\hline $65+$ & 4 & 4 & 5 & 5 & 0 & 14 \\
\hline $\begin{array}{l}\text { Networked } \\
\text { Individuals }\end{array}$ & 4 & 5 & 5 & 6 & 4 & 31 \\
\hline Under 35 & 7 & 6 & 9 & 7 & 5 & 34 \\
\hline $35-50$ & 5 & 3 & 5 & 5 & 6 & 31 \\
\hline $51-64$ & 4 & 5 & 7 & 5 & 5 & 31 \\
\hline $65+$ & 4 & 5 & 5 & 15 & 0 & 31 \\
\hline $\begin{array}{l}\text { Socially } \\
\text { Bounded } \\
\text { Individuals } \\
\end{array}$ & 4 & 2 & 5 & 4 & 2 & 18 \\
\hline Under 35 & 4 & 8 & 7 & 15 & 0 & 34 \\
\hline $35-50$ & 4 & 2 & 5 & 3 & 9 & 25 \\
\hline 51-64 & 4 & 2 & 3 & 4 & 2 & 14 \\
\hline $65+$ & 4 & 2 & 5 & 5 & 0 & 23 \\
\hline $\begin{array}{l}\text { Socially } \\
\text { Limited } \\
\text { Individuals }\end{array}$ & 4 & 3 & 4 & 3 & 0 & 14 \\
\hline Under 35 & N/A & N/A & $\mathrm{N} / \mathrm{A}$ & N/A & N/A & N/A \\
\hline $35-50$ & 4 & 3 & 4 & 1 & 2 & 14 \\
\hline 51-64 & 4 & 2 & 3 & 3 & 0 & 12 \\
\hline $65+$ & 4 & 4 & 5 & 3 & 0 & 15 \\
\hline
\end{tabular}


Freelance reporter James McFinley (P24, M, 323) had 28 social ties across all role relations due to the nature of his job as a reporter. Building and maintaining his social network came easy to him:

\section{I certainly have no problem connecting with people.}

Being active on Facebook and Twitter led to James expanding his personal network both professionally and socially. He used digital media though for different social purposes and was selective with whom he connected on Facebook,

On Facebook, I keep it very limited to people who I know, but on Twitter, no.

Even though Abasi Wangai (P30, M, 27), who had 20 social ties, reported that he had lots of friends, he still wanted to further expand his personal network.

I have so many friends already and it's an effort to make new friends, but it all depends if you connect right away. But I'm very outgoing. Everywhere I go, usually I talk to people.

Being involved in social groups can multiply the number of ties. Through involvement in his mosque, Abbas Farrukh (P17, M, 27) had an expansive and diverse social network (39 ties), meeting other parents because of children and maintaining old friendships. Because of the number of social ties, Abbas preferred to meet with his friends in groups.

Most of the friends I hang out with now are friends for ten years, twelve years now. We just hang out in groups. Once in a while individually, as well. Even like some of my friends who have families, like children as well. We also meet in families.

Having a limited number of ties can be related to personal networks shrinking with age, the decline is often reported as a challenge particularly for the aging population (Cornwell \& Waite, 2009). For example, James May (P34, M, 56) reported that his ties had diminished over time and when asked how often he sees his family, he said,

Well there isn't a lot left. There aren't the family, it's shrinking a bit as we get older.

\footnotetext{
${ }^{3}$ All names are pseudonyms and contextualized with basic participant information (interview ID, gender, and age).
} 
Elena Feyer (P96, W, 75) used to see her neighbors a lot, but less often now, as her neighborhood continues to change. Her older-adult neighbors had either died or moved out:

On our streets, we have a lot of young professionals, I suppose you could say, who have moved in. [rather than the] older people like myself [who were] there since these homes were built. And so most of them are gone now, either deceased or just moved on to wherever.

Role Diversity: The age-groups varied in the diversity of roles they contained (Table 1).

Although there was little variation across age-groups in the 4 or 5 immediate kin that participants reported $^{4}$, there was greater variation in the number of ties reported in the other social roles. Participants in the 35-50 and 51-64 age-groups reported fewer extended kin than those under 35 and over 65 . This suggests that extended kin played less of a role in middle-age by comparison with early adulthood and late adulthood. The number of friends and neighbors reported was greatest for participants under 35, with a median of $8.5($ S.D. $=2.8)$ and 7 (S.D. $=10.7)$, respectively. The median for workmate ties was largest for those under 35 and 35-50, while surprisingly few workmate ties were reported by the 51-64 age-group. Also, very few workmate ties were reported by the often-retired $65+$ participants, with the exception of Brian Lawrence (P72, M, 65) who reported 15 ties (Quan-Haase, Mo, \& Wellman, 2017).

Two age-related patterns emerged. First, those under 35 had larger and more diverse networks, with higher median values for all role relations except for workmates. The 35-50 age group reported the greatest median for workmates, as their workplace was an important place for socialization. Second, older adults remained well-connected (except for having few workmates in their retirement), with greater network diversity (when excluding workmates) than middleaged adults--the 35-64 and 35-50 age-groups.

\footnotetext{
${ }^{4}$ Where network members could have multiple roles, such as "sibling" and "friend," we standardized on the role most important to their relationship--usually kinship.
} 
Social Group Involvement: The East Yorkers were involved in one or two social groups, with a median membership of $1(S . D .=1.9$; Table 2$)$. Older adults $(65+)$ doubled that with a median of $2(S . D .=2.6)$; perhaps reflecting their more available time with retirement and their age-group cohort's greater involvement in groups throughout their lives (Brokaw, 1998; Putnam, 2000). Nearly one-third (31) of the participants did not report belonging to any social group-their networks were comprised of tie relations outside of formal social groups like book clubs and volunteer organizations.

\section{Table 2.}

Median network size, diversity, and involvement by type of connectivity and age

\begin{tabular}{|c|c|c|c|}
\hline & Network Size & $\begin{array}{l}\text { Social Group } \\
\text { Involvement }\end{array}$ & $\begin{array}{l}\text { Network } \\
\text { Diversity }\end{array}$ \\
\hline All Participants & 22 & 1 & 7 \\
\hline Under 35 & 34 & 1 & 8 \\
\hline $35-50$ & 21 & 1 & 8 \\
\hline $51-64$ & 15 & 1 & 7 \\
\hline $65+$ & 14 & 2 & 7 \\
\hline $\begin{array}{l}\text { Networked } \\
\text { Individuals }\end{array}$ & 31 & 2 & 9 \\
\hline Under 35 & 34 & 1 & 10 \\
\hline $35-50$ & 31 & 1 & 9 \\
\hline 51-64 & 31 & 3 & 10 \\
\hline $65+$ & 31 & 2 & 8 \\
\hline $\begin{array}{l}\text { Socially } \\
\text { Bounded } \\
\text { Individuals }\end{array}$ & 18 & 2 & 7 \\
\hline Under 35 & 34 & 1 & 6 \\
\hline $35-50$ & 25 & 0 & 8 \\
\hline $51-64$ & 14 & 2 & 7 \\
\hline
\end{tabular}




\begin{tabular}{llll}
\hline $\mathbf{6 5}+$ & 23 & 2 & 7 \\
\hline $\begin{array}{l}\text { Socially Limited } \\
\text { Individuals }\end{array}$ & 14 & 0 & 6 \\
\hline Under 35 & N/A & N/A & N/A \\
$\mathbf{3 5 - 5 0}$ & 14 & 1 & 7 \\
$\mathbf{5 1 - 6 4}$ & 12 & 0 & 5 \\
$\mathbf{6 5 +}$ & 15 & 0 & 6 \\
\hline
\end{tabular}

Digital Media: East Yorkers under the age of 35 relied on many digital media channels (Figure 1). Their use of digital media channels stemmed from the ability to be reached anytime and anywhere because of quick, rapid exchanges of messages, social support, and information. Not only did digital media channels aid in the expansion and diversity of personal networks, but some participants (under 35 and 35-50) also turned to social media such as LinkedIn and Twitter for professional networking.

Twitter is more for work purposes and LinkedIn is definitely work-related (Valerie Rosenfeld, P27, W, 40).

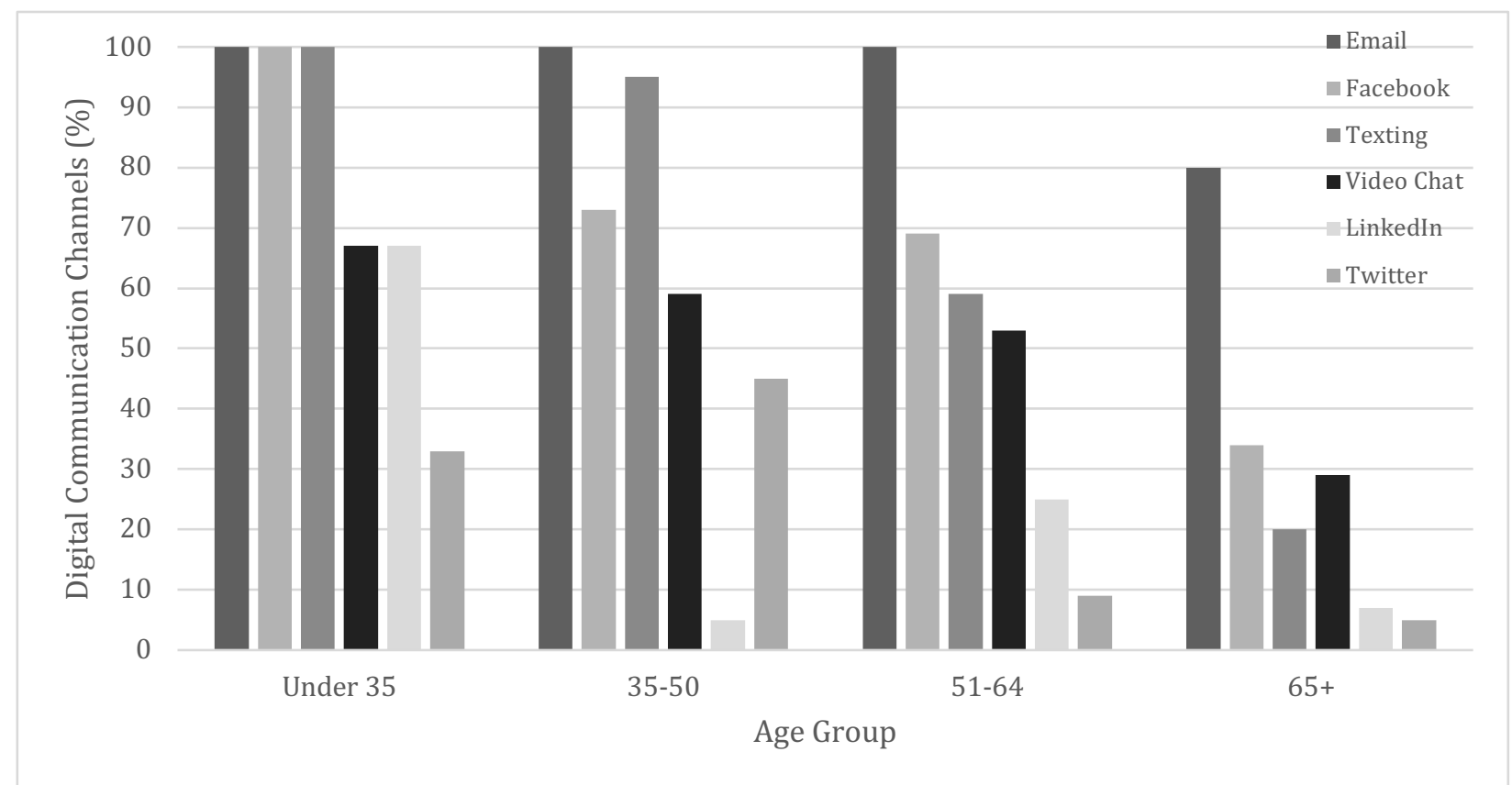

Figure 1. Use of digital communication channels by age-group 
Although middle-aged East Yorkers (35-64) often used digital media, this was to a lesser extent than those under 35. They used digital media to foster, enhance, and expand communication capabilities, valuing the ability for communication to occur anytime, anyplace, anywhere. As David Hawthorne (P74, M, 61) said:

My cellphone, for sure, because now I can communicate with anybody, anywhere, anytime.

The situation was somewhat different for many middle-aged and older adult (65+) participants who reminisced about non-digital communication but had added digital media to their repertoire. For example, David Hawthorne (P74, M, 61) converted to a smartphone, saying:

Well yeah, okay, why not? Let's give it a whirl.

Despite using digital media at lesser rates than their younger counterparts, older adults $(65+)$ embraced the ability to connect through digital media channels to feel more connected with social ties at a distance and to participate in intergenerational connections--something that might not have been possible without digital media (Quan-Haase, Mo, \& Wellman, 2017; QuanHaase, Wang, et al., 2018). As Jack Holms (P7, M, 73) said:

I'm probably communicating with friends a bit more [now with digital media].

Some middle-aged and older adults were ambivalent about using digital media for socialization. They had some hesitancy, fear, and skepticism about the quality of communication being fostered, but most also recognized that digital media had made communication easier, valuing its affordances (Quan-Haase, Wang, et al., 2018).

The [cell]phone has made a huge difference. You can send pictures, you can talk instantly. You can phone someone when you're walking down the street when you couldn't years ago...But I think it's enabled more communication, but maybe not the right communication. You're becoming too available when you shouldn't have to be...I don't think we should be 24/7 ever...I think technology has challenged that work/life 
balance because you're addicted to your phone. You're a prisoner of your phone sometimes (Elizabeth Polly, P44, W, 46).

As with network size, the number of digital media channels used varied across agegroups (Figure 1). Email was prevalent in all age groups, yet other digital media channels like Twitter were mostly used by the under 35 . Although younger participants were more digitally connected--using more digital media channels at higher rates than older East Yorkers, most older East Yorkers owned several digital devices (PC or laptop and cellphone) and had some digital literacy, with many learning to use additional digital media channels like Skype and Facebook (Quan-Haase, Williams, et al., 2018; Wang et al., 2018).

\section{Research Question 2: Do Networked, Socially Bounded, and Socially Limited individuals} differ in their use of digital media?

Despite the proliferation of physical and social networks in the Global North (Castells, 2000), not all members of these networked societies are themselves networked individuals. We found that $35 \%$ of the East Yorkers were Networked Individuals, 36\% were Socially Bounded, and 29\% were Socially Limited. Networked Individuals had markedly larger networks with a more diverse variety of roles than the Socially Bounded, who had somewhat smaller and less diverse networks, and the Socially Limited, who had markedly smaller, less diverse networks, and were rarely involved in social groups (Table 2). Limited Individuals had about equal kin ties to Networked Individuals and Bounded Individuals; but lower medians for friendship, neighbor, and workmate ties distinguished them in their overall connectivity. They also participated in no social groups, whereas Networked Individuals and Bounded Individuals had a median value of social group involvement of $2(S . D .=2.1)$ and $2(S . D .=1.9)$, respectively.

Younger adults were the most likely to be Networked Individuals: two-thirds of those aged under 35 were Networked Individuals and one-third were Socially Bounded, with none 
being Socially Limited (Figure 2). The percentage of Networked Individuals declined in the 3550 and 51-64 age-groups to $41 \%$ and $28 \%$, respectively. There was surprisingly an equal percentage of Networked Individuals in the older adult (65+) age-group as in the 51-64 agegroup; in fact, the older adults were equally split across the three categories with $32 \%$ being Networked, 32\% Bounded, and 36\% Limited.

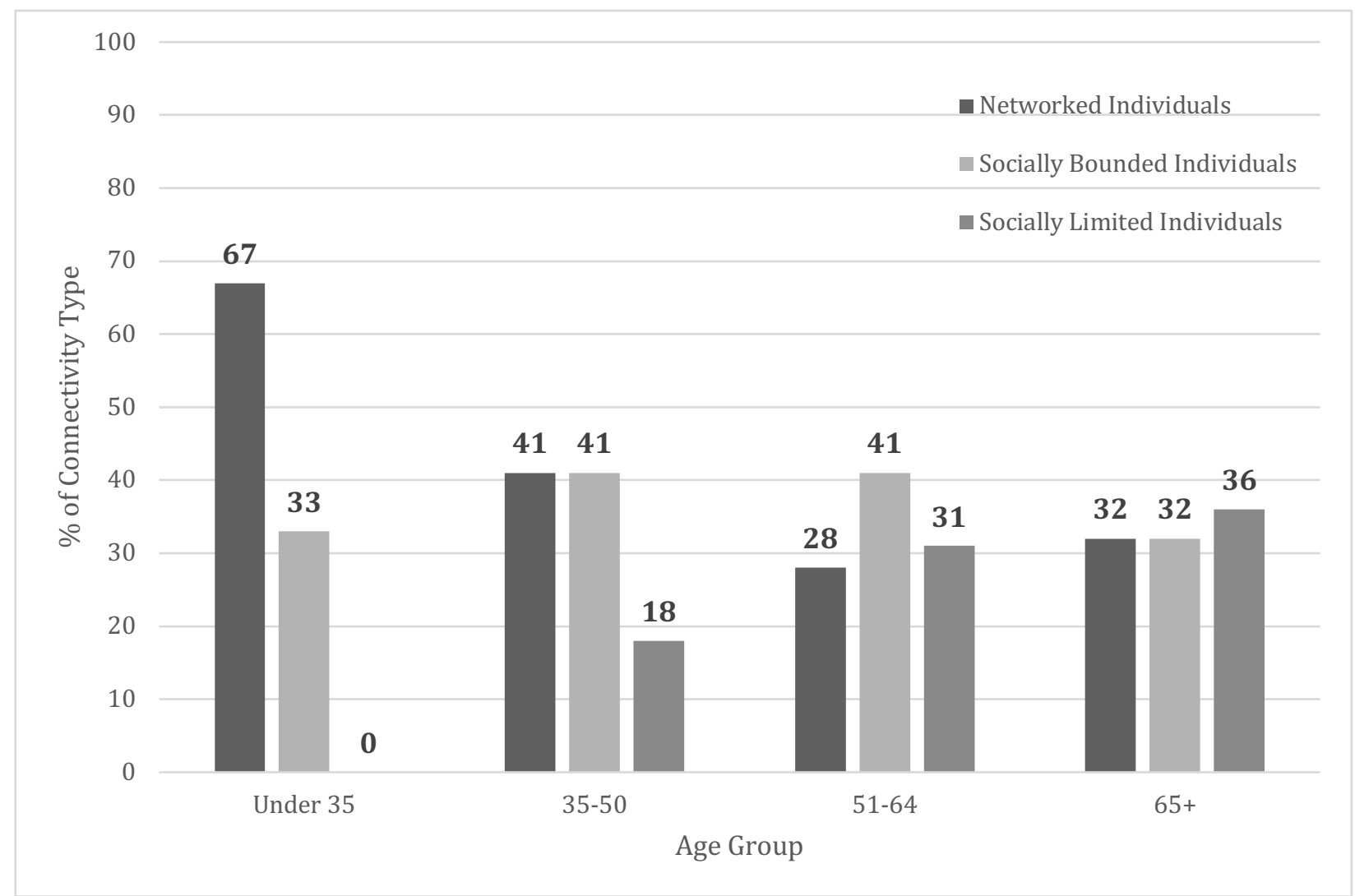

Figure 2. Type of connectivity by age-group

Networked Individuals turned to digital media for an array of purposes such as expanding their social networks, ease of connectivity, and maintenance of personal and professional social ties (see also Lai, 2019). Networked Individuals had a median of five communication $(S . D .=1.9)$ channels and a median of three digital media channels $(S . D .=2$;

Figures 3). For example, Harry Jones (P42, M, 40) told us: 
Of course, it's easier to connect. I do connect a lot more frequently with cousins in Montreal and whatnot. When people are so far that you can't see them, we Skype them. We'll have a brief conversation on phones and arrange a time to hang out on Skype...I enjoy Facetime than simply talking to someone over the phone, especially if it's someone you care about. It makes maintaining relationships easier and I can stay connected with people I care about.

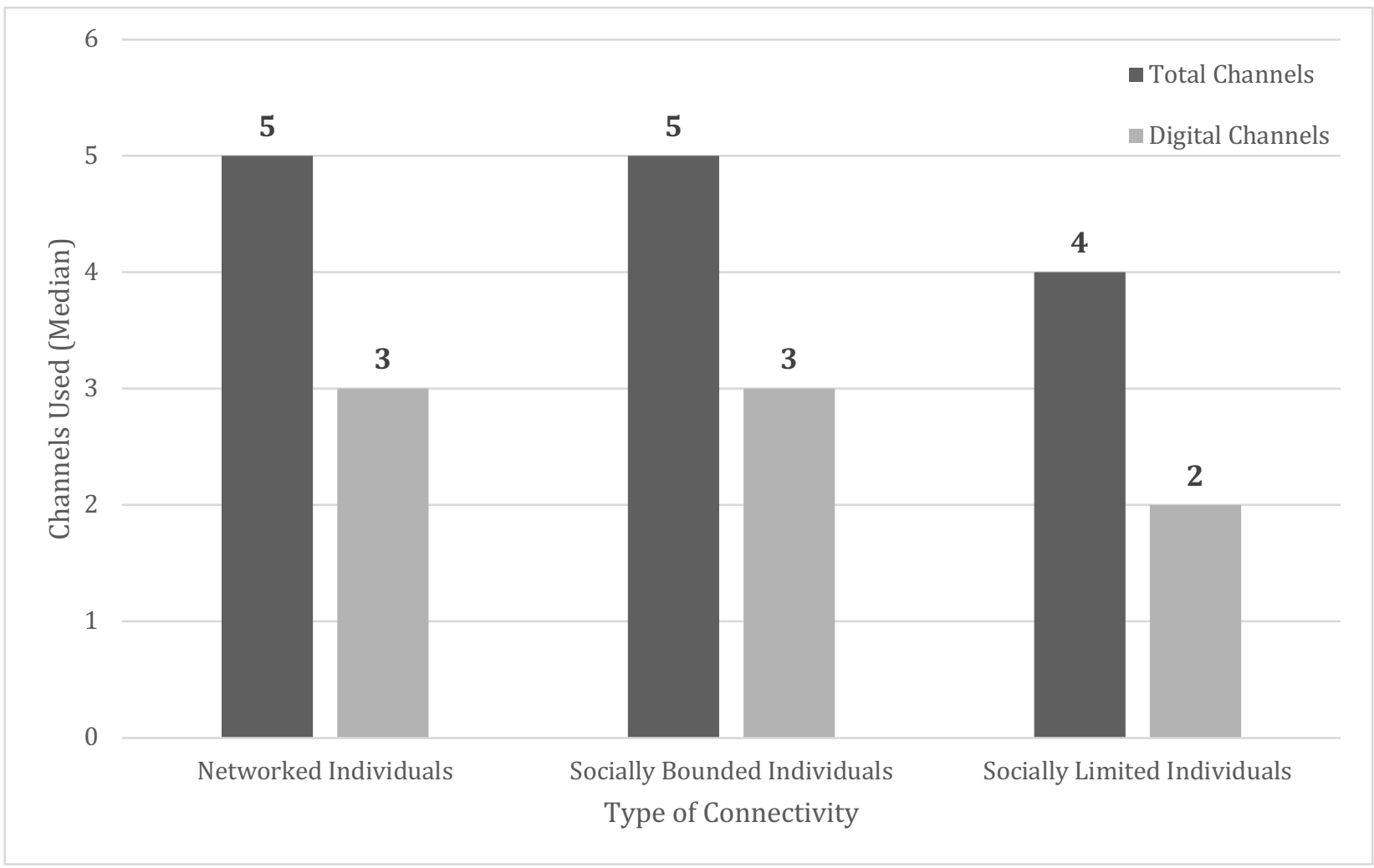

Figure 3. Use of communication channels by type of connectivity

Similarly positive, Sidney Cooper (P26, W, 68) felt digital media made it easier to keep up with friends, in particular those who have moved away.

That is good because it helps you keep in touch with your old friends that are scattered throughout the world.

Email was basic for almost all participants and supported a range of role relations (Figure 4). For instance, a British friend emailed Networked Saad Bakker (P41, M, 34) that he was coming to Canada for a conference. This led to Saad hosting and rekindling an old friendship with someone he had not seen over twelve years. 


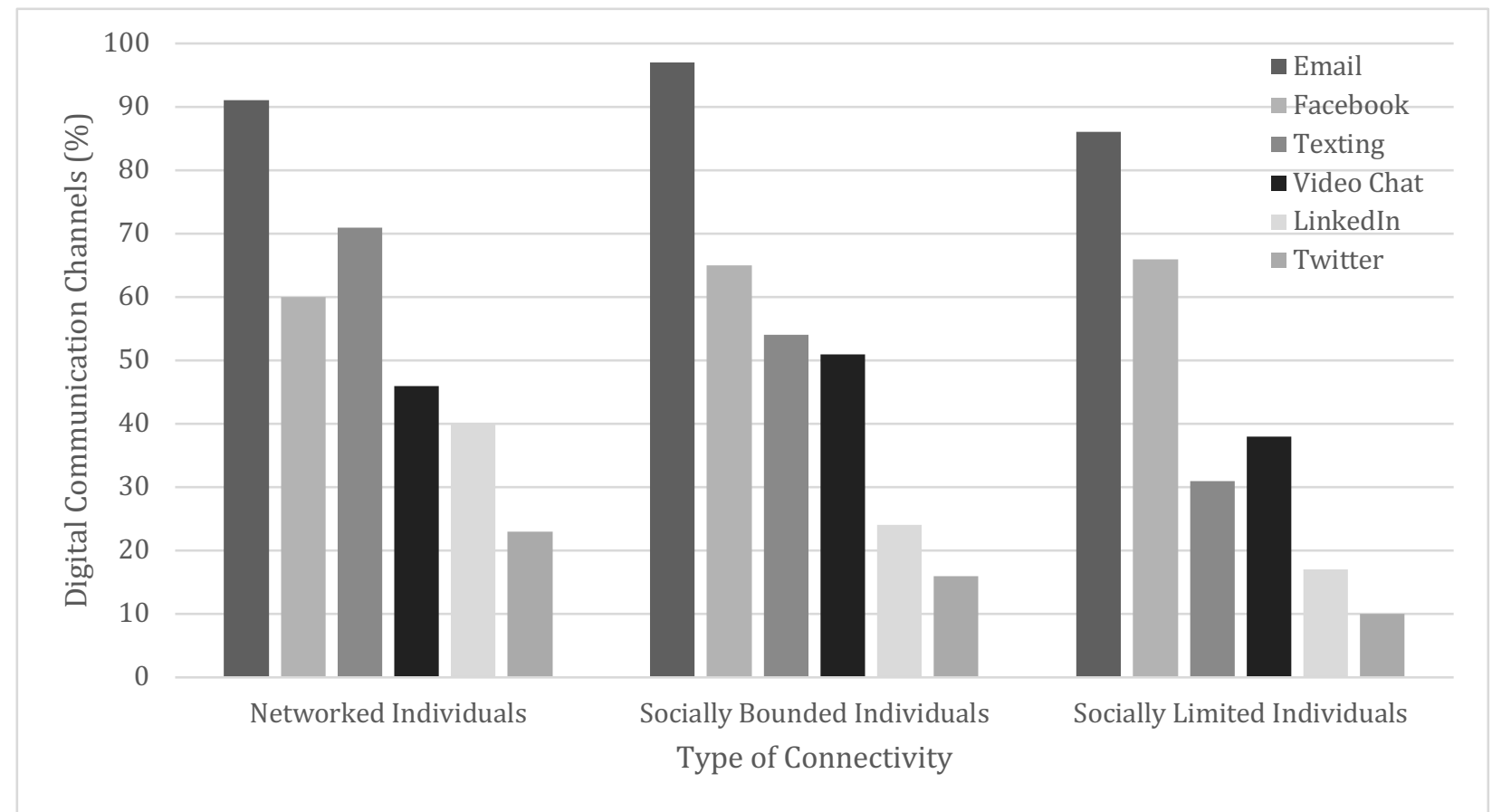

Figure 4. Use of digital communication channels by type of connectivity

Most Networked participants used Facebook. They saw it as a way to keep in touch with a variety of ties, such as extended kin and friends, despite not being in regular and frequent contact. For example, Maggie Darling (P22, W, 60) used Facebook for finding old friends and exchanging messages, she noted:

\section{Facebook has opened up a lot for me.}

Networked Individuals were also keen to introduce their friends to one another, which often led to an interweaving of distinct role relations, as Duncan Robertson (P33, M, 83) explained:

Because they would find each other interesting. Just people getting together for an interesting evening.

Similarly, James McFinley (P24, M, 32) said he would often introduce friends with similar interests to one another online. 
With sizable social networks, digital media allowed Networked Individuals to maneuver across separate sets of people and social groups, often with different and diverse backgrounds and interests. For example, musician Brian Lawrence (P72, M, 65) frequently got together with workmates who were also fellow musicians and used email to communicate with a variety of role relations.

Oh, email. Email. But I may call sometimes too and say 'Are you free?' You know. Whatever. But usually it's better email.

Networked Individuals often reported taking active roles in the more formally organized social groups they belonged to, such as being leaders, organizers, or event coordinators. For example, David Hawthorne (P74, M, 61) who had a large personal network, was also an active member of three groups. As a proud member of a veterans' group, David often aided in the collection of donations in addition to his involvement in a variety of events sponsored by the main Canadian veterans' organization:

Once a year we go on a ride [to support] the Highway of Heroes, the first Saturday in June, and last year I collected two thousand dollars [for charity] ...I belong to the Legion and I'm a committee member....So yes, it overlaps.

Socially Bounded individuals differed from Networked Individuals in the scope, magnitude, and breadth of their networks. While some had many ties, these were concentrated on intimate family and friends, and they often socialized with the same people for different activities.

We originally had expected that Networked Individuals in comparison to Bounded Individuals would make much greater use of communication channels and in particular of digital channels to maintain their extensive and diverse personal relations. However, we found that the median of 5 communication channels $(S . D .=1.6)$ and the median of 3 digital communication channels $(S . D .=1.6)$ was the same for Bounded East Yorkers as it was for Networked East 
Yorkers (Figure 3). Although Bounded individuals saw the many benefits of digital media for communication, they were digitally parochial, concentrating on socially close family and friends. This was reflected in their activity on the more focused forms of digital media--such as email, Facebook, and video chat--rather than on the more fragmented and open Twitter (Figure 4). For example, Bounded Rebecca White (P21, W, 30) used digital media--especially her cellphone--for texting and chatting with close friends.

It's made it easier to communicate with people that I care about...To maintain my relationships and my friendships because after a while you don't talk to people for so long, it's kind of sometimes awkward to come back in and pick up where you left off.

Similarly, Adam Ford (P46, M, 47) said his busy lifestyle made it hard to maintain connections with current friends, let alone make new ones.

In all honesty we don't really seek out new friends because we have a lot of existing friends we don't have enough time to see and we have a very big family.

And Beverley McShane (P2, W, 75) said she regularly got together with two close friends for social outings.

The friends that I go out with are both widows, and this is just part of life... We go out for lunch and we go to a shopping mall, and we just go around to the different shopping malls and look at stuff and walk around.

Socially Limited participants were often hesitant in turning to digital media to facilitate meaningful, intimate communication with their ties. They used fewer communication channels: a median of four communication channels $(S . D .=1.6)$ and two digital media channels (S.D. $=1.6$; Figure 3). They used digital media primarily to keep up-to-date and to socialize as a supplement to traditional face-to-face and phone communication (Figure 4). In fact, Limited Individuals questioned the value of a heavy reliance on digital media in everyday life. Blair O'Donnell (P8, M, 70) wondering:

Sometimes I ask the question: apart from communicating with people in certain ways, what purpose does technology serve in the first place? 
Some Limited East Yorkers used digital media to connect with their ties. For example,

Carol Holman (P14, W, 36) said she would sometimes use Facebook or email to arrange get togethers with family and friends, although she preferred phone calls. She said she would rather spend quality time in-person with a few people, and she shied away from organizing larger gatherings:

It can be complicated to try and get a bunch of people together.

Some Limited participants, such as Samar Muhammad (P83, M, 82), said Facebook was a great vehicle for information, but wondered about its capabilities to support social interactions:

How do you communicate?

They were skeptical about digital media meeting their communication needs, in part because they tended to be older and hesitant about adopting new technologies (see also QuanHaase, Williams, et al., 2018; Wang et al., 2018).

I'm not so involved in all of that stuff because of my age. I feel that it kind of came after me. It's something that I didn't have to be concerned with, but now I'm starting to get involved with it more...I'm one of the old dinosaurs that still likes the telephone. I like an instant answer; I don't want to wait for someone to get back to me on the email (Jason Smith, P66, M, 55).

Similarly, Catherine O’Henly (P53, W, 67) felt:

If you send someone an email, you're not talking with them. They'll get it, and then they read it and respond. I prefer to call up on the phone and talk to them directly.

\section{Research Question 3: How does social connectivity and digital media use vary in different} stages of the life course?

Consistent with other research, we found that younger adults made the most extensive and varied use of digital media (Smith \& Anderson, 2018). Our own research also has shown that younger adults are more likely to be Networked Individuals. But this was not a stark young/old dichotomy. About one-third of older adults were also Networked although they used digital 
media less (see also Wang et al., 2018). Many older adults were active in multiple networks, some were physically active in 'the new old age' (Jacoby, 2011), and some continued to do paid work. We also learned that people in different age-groups tended to conserve media, sticking with the digital media they were most accustomed to (often from earlier life stages or work experiences).

As younger adults have grown up with digital media and were more likely to use it, we wondered if it was age or networked individualism that was leading to extensive use of digital media. As preliminary analysis found similar patterns for all the age-groups under 65 (Figure 5a), to make a small sample tractable, we compared participants who were less than 65 years old with those who were older (Figure 5b). We found both age and networked individualism to be important: For both, those younger and older than 65, it was the Networked Individuals who made the more extensive use of digital media. Lacking longitudinal data, we do not know which came first, being networked or extensive use of digital media, although we suspect the former. 


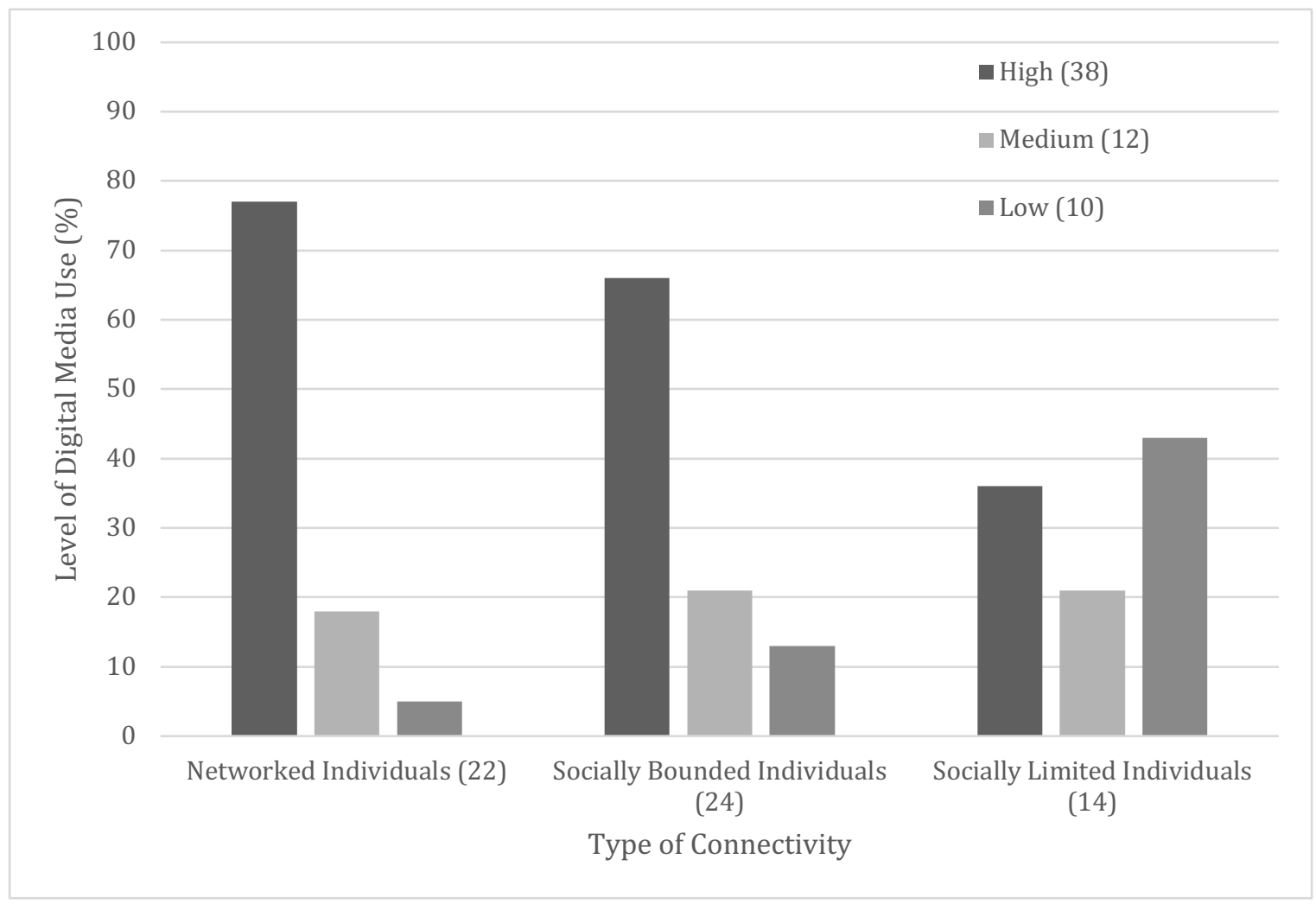

Figure 5a: Level of digital media use by type of connectivity (Under 65)

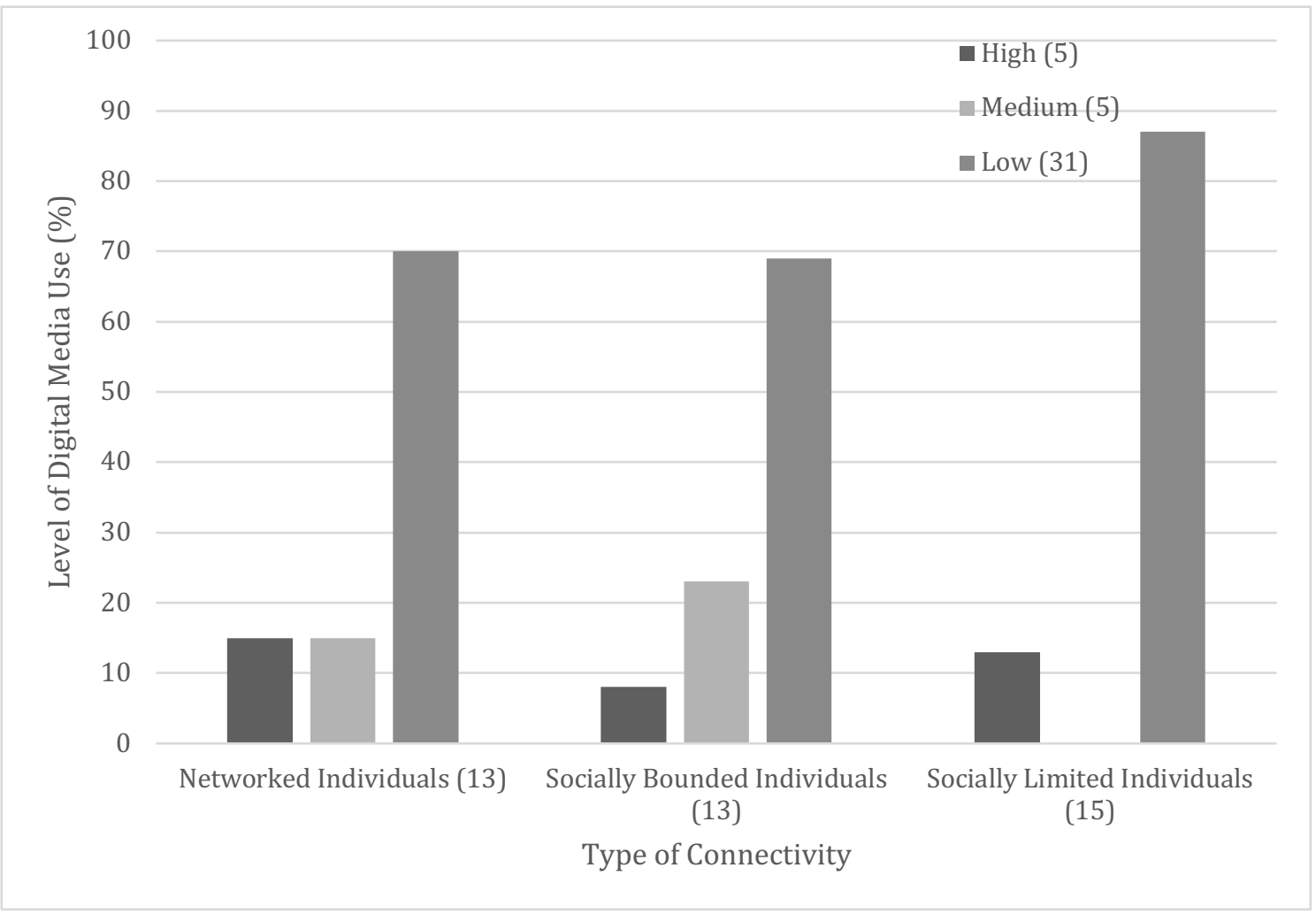

Figure $5 b$. Level of digital media use by type of connectivity (65+) 


\section{Discussion}

A life course perspective has allowed us to discern life circumstances and contextual factors that influence personal networks. We examined age ranges as proxies for life stages although we realize that this is simplified and are sensitive to the fact that adulthood is comprised of a wide range of changes and that learning occurs constantly. We tried to stay open during coding and analysis to the variations within life stages and the range of past experiences that inform a person's current life stage, as these represent a continuation of previous practices and activities. For example, past experience with digital media at work often predicted continued use in retirement.

Our research has shown how East York adults integrated in-person meetings, phone calls, and digital media to keep in contact with diverse personal networks comprised of friends, kin, and neighbors and how they participated in social groups such as book clubs and varied voluntary organizations. A majority of East York adults found digital media to be handy, low-cost, and visually rich (Wellman et al., 2006): the technology was valued and routinely incorporated into their lives. Relying primarily on email, Facebook, texting, and video chat, the East Yorkers used digital media to maintain, coordinate, strengthen--and sometimes grow--social ties. Contradicting fears that digital media was inadequate for meaningful contact (Turkle, 2011; Dotson, 2017), these East Yorkers valued companionship via digital media as an important complement to face-to-face contact. Coming from other parts of Canada and the world, they appreciated digital media's longdistance, often transnational, connectivity.

Using descriptive statistics and in-depth interviews, we were better able to understand the personal networks in a networked society regarding who was more or less networked, and how this affected them socially. We found that according to our criteria approximately one-third of the 
East Yorkers were Networked Individuals; one-third were Socially Bounded, and one-third were Socially Limited. We found that Networked Individuals almost simultaneously moved within and between an array of diverse, partial networks, both local and long distance. We were surprised that more participants were not identifiable as Networked Individuals although this is partially attributable to the high proportion of older adults in our sample (Wang et al., 2018).

We found differences in the distribution of the three types of connectivity across agegroups. Although younger adults were the most likely to be Networked Individuals, not all were Networked Individuals, with a third being Socially Bounded. No younger adults were Socially Limited. Although our sample is small, the social adeptness of younger adults is consistent with other systematic research (e.g., Hampton, 2016; Robinson, 2018) showing that complaints about socially inept and isolated digital natives have been overstated by alarmists working from armchairs, anecdotes, or unusual samples.

We found fewer Networked Individuals in the 35-50 and 51-64 age groups. Yet, there were surprisingly more Networked Individuals in the older adults (65+) age group than in the 51-64 age group; the older adults were equally split across the three categories. Many older adults found that digital media had helped them to stay active and connected, especially when they continued the digital media involvement they had started when younger. Lacking longitudinal data, we do not know if age-group differences reflect different generational behaviors (and computer adeptness) by younger adults, or if as younger adults grow older, they will be less likely to be Networked Individuals.

Networked Individuals used somewhat more digital channels than Socially Bounded individuals and much more than Socially Limited individuals. To be sure, those who are Bounded were often appreciable users of digital media--but their use was more within a small set 
of groups. Moreover, networked individualism did not mean that all ties were equally interacted with: Some of an individual's multiple, partial networks were stronger, more diverse, and more closely knit than others (Quan-Haase, Wang, et al., 2018; Wang et al., 2018).

Thus, the three categories were indicative rather than strong boundaries. Networked Individuals tended to interact more with only some of their multiple networks; Socially Bounded individuals did not always operate within the same small groups; Socially Limited individuals were not isolated--they just used digital media to a lesser extent to connect with their smaller number of ties. In such ways, all the participants were networked to some extent.

\section{Limitations and Implications for Future Research}

Our typology proposed three connectivity types: Networked, Bounded, and Limited individuals. Future research could provide additional insight into the validity, reliability, and usefulness of this tripartite categorization. We have proposed these categories as ideal types but realize that individuals may move between types over the life course depending on key life events, and may also be categorized differently if other connectivity measures are chosen.

The current study aimed to develop a typology of social connectivity and test the concept of networked individualism. One of our limitations was the complexity in establishing what structural features of a network would be most valuable in categorizing individuals into social connectivity types. The proposed approach uses a combined measure of network size, network composition, network diversity, and involvement in social groups. The approach uses the median within age-groups as a means to gauge structural connectivity although not much research exists to date on how effective the median is as a means for categorization of network connectivity. Future research using survey data, a larger sample size, and different social contexts could evaluate this. It would also facilitate fuller evaluation of the relation of networked individualism 
and digital media use to such matters as gender, ethnicity, family situation, work situation, and socioeconomic status. The age distribution of our sample affected our analysis, as we only had 6 participants under 35. Expanding this age-group will be critical for more comprehensive age comparisons. Hence, we view the present study as a first attempt to develop a typology of connectivity across the life course, evaluate the networked individualism concept, and propose new measures of social connectivity.

An additional limitation was the extrapolation from verbose interview responses to counts of social ties. The in-depth semi-structured interviews provided valuable detail on social ties and the nature of these ties, but a survey would have added more precision to the counts used for measures like network size, role relation, and group involvement. The interviews did have the advantage of allowing for clarification of responses and follow-up questions.

Another limitation is that our interviews were conducted in 2013-2014, a long time ago in the rapidly changing digital era. With the proliferation of the digital media since then, many participants are probably using a wider variety of communication channels than when we interviewed them--especially turning to smartphones. We believe that this would entail a greater shift to being Networked Individuals.

Every study suggests new research opportunities. When we began our analysis, we were so excited by the opportunity to document networked individualism that we were gobsmacked when Networked Individuals proved to be less than a majority of the study participants. Being Networked Individuals ourselves undoubtedly added to our myopia.

On reflection, we believe that we have discovered the similar tendencies that Merton (1957) had labeled as "cosmopolitans" and "locals". The cosmopolitans are Networked Individuals--reaching out in complex multiple networks: what Burt (2001) called "bridging 
capital" - having relatively high contact with dissimilar others and diversified situations and ideas. By contrast, the Socially Bounded or Limited stay home and remain stably connected to similar others via "bonding capital" (Coleman, 1988). We believe that these tendencies are not just an artifact of our skewed and small sample--after all, we were studying the residents of the large multicultural Toronto metropolitan area. Rather, we suspect that this bifurcation is endemic in many societies, networked or not.

We also suggest extending this research into understanding if Networked Individuals have more intercultural sensitivity than more parochial Bounded and Limited individuals (Bennett, 1994). We suspect that this bifurcation may be associated with the more rancorous political tendencies being manifested throughout the Global North, such as the British Brexit fight, the welcoming/disdaining immigration debates in Europe and Australia, the banning of wearing hijabs in the Quebec public service, and most clearly as personified in the United States by the contrast of the Networked Barack Obama with the Bounded followers of Donald Trump who have felt like "strangers in their own land" (Hochschild, 2016; Frank, 2004) or are benignly staying home to cultivate their own Candidean garden (Voltaire, 1759) as the networked society has blossomed.

\section{Conclusions}

Networked individuals may take advantage of the many features and functions for connectivity afforded by digital media. Nevertheless, relying on digital media is neither a necessary nor sufficient precondition for being a Networked Individual, as they have existed centuries ago (Wellman \& Wetherell, 1996).

Our research found that Networked Individuals of all ages used digital media to maneuver across separate sets of people and groups, often with diverse backgrounds and 
interests. They not only were more connected, but they actively sought to interconnect their friends. They particularly liked social media for making interest-based connections and keeping in touch with far-flung ties. By contrast, Socially Bounded individuals were digitally parochial: content to use digital media to maintain their existing relationships within bounded sets of roles and groups. Their networks were weaker in role diversity, size, and breadth compared to Networked Individuals. They used digital media mostly to maintain connections with social ties rather than to actively engage with new ones. The Socially Limited used digital media hesitantly and sometimes grudgingly, seeing it as a pale substitute to face-to-face contact rather than as a gap-filling complement.

In thinking of the term "Networked Individual," it may be a common misconception to think only of a young adult who uses a plethora of digital communication channels and is reachable at any given moment because they are always online or have their cellphones at close reach. While this may be true in some cases, not all Networked Individuals were young--or even middle-aged--adults. We found $32 \%$ of those $65+$ were Networked Individuals who countered the age-based misconception. We also found that communication channels were used as much by Socially Bounded individuals and to some extent by Socially Limited individuals.

Although most younger adults were Networked Individuals, not all fell in this group. Most importantly there were no Socially Limited Individuals in the less than 35 age-group, calling into questions fears of younger generations being atomized by digital media (e.g., Twenge, 2017). We did find that younger adults used digital media extensively for socializing-for this group it was an integral part of their social life. Yet, we did not find that younger adults regarded digital media as a barrier to forming meaningful and diverse social ties. Rather, it facilitated their connectivity. 
As society becomes more digital, fears have arisen about older generations being left behind (e.g., Fields, 2019). Narratives often paint older adults as lonely and disconnected. However, contrary to such assumptions, not all younger adults were Networked Individuals, and not all older adults were Socially Limited or Socially Bounded. Even though many older and middle-aged adults primarily relied on familiar forms of communication such as in-person meetings or telephone calls or stuck to familiar modes such as email, most were learning, using, and integrating digital media in their communication with their social ties. We found that many older adults, and even more middle-aged individuals, were networked and expanding their digital media use, even if not always to the extent of younger adults. Large-scale U.S. survey data show that in this respect East York reflects the North American norm (Rainie \& Wellman, 2019). Despite the oy veying of dystopian pundits mesmerized by occasional anecdotes, in practice, both Networked and Bounded individuals swipe right on digital media to enhance their lives.

\section{Acknowledgements}

We are grateful for the financial support of the Social Science and Humanities Research Council of Canada. We are grateful to those who have advised and abetted us, especially those who transcribed and coded the interviews, as well as Christian Beermann, Brent Berry, Isioma Elueze, Maria Kicevski, Amritorupa Sen, Lilia Smale, Helen Hua Wang, and Renwen Alice Zhang. Most of all, we owe immense gratitude to the residents of East York who welcomed us into their homes. Grant Number: SSHRC 435-2015-1444

Ethical Guidelines: We confirm that this paper meets the ethical guidelines of the Canadian universities and granting agency involved.

Competing and Conflicts of Interest: We confirm that we have no competing interests of any kind, financial or intellectual, in the research covered by this manuscript. We confirm that the Authors have no conflicts of interest to disclose. 


\section{References}

Agneessens, F., Waege, H., \& Lievens, J. (2006). Diversity in social support by role relations, Social Networks, 28(4), 427-441.

Anderson, B. Y. M. (2015). American demographics of digital device ownership. Retrieved from http://www.pewinternet.org/2015/10/29/the-demographics-of-device-ownership.

Bennett, M. (1994). Towards ethnorelativism. In R. M. Paige (Ed.), Education for the intercultural experience (2nd ed., pp. 21-71). Boston: Nicholas Brealey.

boyd, d. (2007). Why youth (heart) social network sites. In. D. Buckingham (Ed.), Youth, identity and digital media, Cambridge, MA: MIT Press.

Braun V. \& Clarke V. (2006). Using thematic analysis in psychology, Qualitative Research in Psychology, 3(2), 77-101.

Brokaw, T. (1998). The greatest generation. New York: Random House.

Burt, R. S. (2001). Structural holes versus network closure as social capital. In N. Lin, K. Cook \& R. S. Burt (Eds.), Social capital (pp. 31-56). New York: Aldine de Gruyter.

Campbell, H. (Ed.). (2012). Digital religion. London: Routledge.

Castells, M. (2000). The rise of the network society (2nd ed.). Oxford: Blackwell.

Chang, P. F., Choi, Y. H., Bazarova, N. N., \& Lockenhoff, C. E. (2015). Age differences in online social networking, Journal of Broadcasting \& Electronic Media, 59(2), 221-239.

Charmaz, K. (2014). Constructing grounded theory ( $2^{\text {nd }}$ Ed.). Thousand Oaks, CA: Sage.

Coleman, J. S. (1988). Social Capital in the Creation of Human Capital. American Journal of Sociology, 44(Supplement), S95-S120.

Cornwell, B. \& Laumann, E. (2008). The social connectedness of older adults, American Sociological Review, 73(2), 185-203. 
Cornwell, E. Y. \& Waite, L. J. (2009). Social disconnectedness, perceived isolation, and health among older adults, Journal of Health and Social Behavior, 50, 31-48.

Dickens, A. P., Richards, S. H., Greaves, C. J., \& Campbell, J. L. (2011). Interventions targeting social isolation in older people, BMC Public Health, 11(647), 1-22.

Dotson, T. (2017). Technically together. Cambridge, MA: MIT Press.

Durkheim, É. (1893 [1993]). The division of labor in society. New York: Macmillan.

Durkheim, É. (1897 [1951]). Suicide (1951 ed.). Glencoe, IL: Free Press.

Elder, G. H., Johnson, M. K., \& Crosnoe, R. (2003). The emergence and development of life course theory. In J.T. Mortimer \& M.J. Shanahan, Handbook of the life course (pp. 3-19). Boston, Springer.

Field, J. (2008). Learning transitions in adult life course, Sociologia, 32, 1-17.

Fields, J. (2019, May 4). We are leaving older adults out of the digital world, TechCrunch. Retrieved from https://techcrunch.com/2019/05/05/we-are-leaving-older-adults-out-ofthe-digitalworld/?utm_source=feedburner\&utm_medium $=$ feed\&utm_campaign $=F e e d \% 3 \mathrm{~A}+\mathrm{TechCr}$ unch $+\% 28$ TechCrunch $\% 29$

Fischer, C. (1982). To dwell among friends. Berkeley: University of California Press.

Florida, R. (2014). The rise of the creative class--revisited: Revised and expanded. New York: Basic Books.

Frank, T. (2004). What's the matter with Kansas. New York: Henry Holt.

Ferguson, N. \& Freymann, E. (2019, May 6). The Coming Generation War, The Atlantic. Retrieved from https://www.theatlantic.com/ideas/archive/2019/05/coming-generationwar/588670/?utm_source=facebook\&utm_campaign=the-atlantic-fb-test-950-1- 
\&utm_content=edit-

promo\&utm_medium $=$ social\&fbclid $=$ IwAR0hn5k0WHummog_Nn2D6szAFkCWAB3M PhLqcgaCuET3PWa-ORS9xDnoOU4

Fung, H. H., Carstensen, L. L., \& Lang, F. R. (2001). Age-related patterns in social networks among European Americans and African Americans, International Journal of Aging and Human Development, 53(3), 185-206.

Gans, H. (1962). The urban villagers. New York: Free Press.

Greer, S. (1962). The emerging city. New York: Free Press.

Hagestad, G. O. \& Uhlenberg, P. (2005). The social separation of old and young, Journal of Social Issues, 61(2), 343-360.

Hampton, K. N. (2016). Persistent and pervasive community, American Behavioral Scientist, 60(1), 101-124.

Hampton, K. N. \& Wellman, B. (2018). Lost and saved... again, Contemporary Sociology, $47(6), 643-651$.

Hargittai, E. (2018). Biases in big data, Social Science Computer Review. https://doi.org/https://doi.org/10.1177/0894439318788322

Hargittai, E. \& Dobransky, K. (2017). Old dogs, new clicks, Canadian Journal of Communication, 42(2), 196-212.

Hochschild, A. R. (2016). Strangers in their own land. New York: New Press.

Hogan, D. P. \& Astone, N. M. (1986). The transition to adulthood, Annual Review of Sociology, $12,109-130$.

Hogan, D. P. (1981). Transitions and social change. New York: Academic Press. Jacoby, S. (2011). Never say die. New York: Knopf. 
Kennedy, T. \& Wellman, B. (2007). The networked household, Information, Communication \& Society, 10(5), 647-670.

Lai, C.-H. (2019). Motivations, usage, and perceived social networks within and beyond social media, Journal of Computer Mediated Communication, 24(3), 126-145.

Loach, K. \& Laverty, P. (2016). I, Daniel Blake. London, Sixteen Films.

Merton, R. (1957). Patterns of Influence: Cosmopolitans and Locals. In R. Merton (Ed.), Social Theory and Social Structure (pp. 387-420). Glencoe, IL: Free Press.

Mok, D., Wellman, B., \& Basu, R. (2007). Did distance matter before the Internet? Social Networks,29(3), 430-461.

Mok, D., Wellman, B., \& Carrasco, J. A. (2010). Does distance matter in the age of the Internet? Urban Studies, 47(13), 2747-2783.

Parsons, T. (1951). The social system.Glencoe, IL: Free Press.

Payne, M. \& Welch, D. (2015). East York. Retrieved from https://www.thecanadianencyclopedia.ca/en/article/east-york/

Peplau, L. (1982). Loneliness. New York: Wiley.

Putnam, R. (2000). Bowling alone. New York: Simon and Schuster.

Quan-Haase, A., Mo, G.Y., \& Wellman, B. (2017). Connected seniors, Information, Communication \& Society, 20(7), 967-998.

Quan-Haase, A., Wang, H., Wellman, B., \& Zhang, A. (2018). Weaving family connections on and offline. In B. B. Neves \& C. Casimiro (Eds.), Connecting families? (pp.57-77). Bristol, UK: Policy Press.

Quan-Haase, A., Williams, C., Kicevski, M., Elueze, I., \& Wellman, B. (2018). Dividing the grey divide, American Behavioral Scientist, 62(9), 1207-1228. 
Rainie, L. \& Wellman, B. (2012). Networked. Cambridge, MA: MIT Press.

Rainie, L., \& Wellman, B. (2019). The triple revolution in everyday life. In M. Graham \& W. Dutton (Eds.), Society and the internet (2nd ed.). Oxford: Oxford University Press.

Robinson, L., Cotton, S. R., Ono, H., Quan-Haase, A., Mesch, G., Chen, W., Schulz, J., Hale, T. M., \& Stern, M. J. (2015). Digital inequalities and why they matter, Information, Communication \& Society, 18(5), 569-582.

Schreurs, K., Quan-Haase, A., \& Martin, K. (2017). Problematizing the digital literacy paradox in the context of older adults' ICT use, Canadian Journal of Communication, 42(2), 359377.

Settersten Jr., R. A. \& Ray, B. (2010). What's going on with young people today? The Future of Children, 20(1), 19-41.

Simmel, G. (1922 [1955]). The web of group affiliations. In K. Wolff (Ed.), Conflict and the web of group affiliations (pp. 125-195). Glencoe, IL: Free Press.

Smith, A. \& Anderson, M. (2018). Social media use in 2018. Pew Research Center. Retrieved from https://www.pewinternet.org/2018/03/01/social-media-use-in-2018/.

Taylor, K. \& Silver, L. (2019). Smartphone ownership is growing rapidly around the world, but not always equally. Pew Research Center. Retrieved from https://www.pewglobal.org/2019/02/05/in-emerging-economies-smartphone-adoptionhas-grown-more-quickly-among-younger-generations/.

Tönnies, F. (1887 [1955]). Community and organization. London: Routledge. Toronto Neighbourhood Guide (n.d.). History of East York. Retrieved from http://www.torontoneighbourhoods.net/neighbourhoods/east-york/east-york/history. 
Toronto Population (2017). World population review - Toronto population 2018. Retrieved from http://worldpopulationreview.com/.

Toronto City Planning (2018). Toronto and East York: City of Toronto Community Council Area Profiles 2016 Census. Retrieved from https://www.toronto.ca/wpcontent/uploads/2018/05/977c-

City_Planning_2016_Census_Profile_2014_Wards_CCA_TorontoEastYork.pdf.

Turkle, S. (2011). Alone together. New York: Basic Books.

Twenge, J. (2017). iGen. New York: Atria.

Uchitelle, L. (2019, May 5). To add jobs, Look past manufacturing, New York Times, pp. BU8-9. Retrieved from https://www.nytimes.com/2019/05/02/business/manufacturing-jobsinfrastructure.html.

Voltaire. (1769 [2016]). Candide. New York Norton.

Walzer, M. (1992). The new tribalism, Dissent, 39, 164-174.

Wang, H., Zhang, R., \& Wellman, B. (2018). Are older adults networked individuals? Information, Communication \& Society, 21(5), 681-696.

Weber, M. (1922[2009]). The theory of social and economic organization, New York: Simon and Schuster.

Wellman, B. (1979). The community question, American Journal of Sociology, 84, 1201-1231.

Wellman, B. \& Leighton, B. (1979). Networks, neighborhoods and communities, Urban Affairs Quarterly, 14, 363-390.

Wellman, B. (1988). The community question re-evaluated. In M. P. Smith (Ed.), Power, community and the city (pp. 81-107). New Brunswick, NJ: Transaction Books. 
Wellman, B., Quan-Haase, A., Witte, J., \& Hampton, K. (2001). Does the Internet increase, decrease, or supplement social capital? American Behavioral Scientist, 45, 437-456.

Wellman, B. \& Wortley, S. (1990). Different strokes from different folks, American Journal of Sociology, 96, 558-588.

Wellman, B. \& Tindall, D. (1993). Reach out and Touch Some Bodies, Progress in Communication Science, 12, 63-94.

Wellman, B. \& Wetherell, C. (1996). Social network analysis of historical communities, History of the Family,1(1), 97-121.

Wellman, B. (2001). Physical place and cyberspace, International Journal of Urban and Regional Research, 25(2), 227-252.

Wellman, B., Hogan, B., Berg, w. K., Boase, J., Carrasco, J.-A., Côté, R., . . Tran, P. (2006). Connected lives. In P. Purcell (Ed.), Networked neighbourhoods. (pp. 157-211). Guildford, UK: Springer.

Wirth, L. (1938). Urbanism as a way of life, American Journal of Sociology, 44, 3-24. 